\title{
Beyond learning by doing: an exploration of critical incidents in outdoor leadership education.
}

\begin{abstract}
.
This paper argues that outdoor leader education and training is generally characterized by the development of procedural skills at the expense of equally crucial but usually ignored, 'soft skills' (for example, contextualized decision making and reflection). Consequently, this risks producing practitioners with a potentially unsophisticated and limited awareness of the holistic outdoor environments and situations and an over-reliance on 'how to' skills which may, in turn, impede the development of links between theory and practice. This paper analyses a research project that undertook the application of critical incident theory to a study of undergraduates in a United Kingdom outdoor leadership degree programme in an attempt to promote and examine the processes of developing 'softer' reflective skills in the students. In addition, the paper's argument and data, while not directly dealing with wider audiences (clients and national qualification bodies), provide inferences and allusions to potential consequent enhanced development and benefits of heightened reflective understanding and practice to these groups.
\end{abstract}

Methodologically, the study examines a range of critical incidents in a purposive homogenous sample of 20 students from a vocational undergraduate outdoor studies course. Students were asked to identify and reflect on critical incidents in practice settings of their own choice. These settings spanned a range of contexts from outdoor centre work in the United Kingdom to assistant leadership positions on educational expeditions in remote locations overseas. Qualitative data analysis was carried out through the use of Interpretative Phenomenological Analysis (IPA).

The findings supported the conceptual premise and indicated that outdoor leadership programmes need to develop a broader and holistic skills base rather than persist with the extant predilection towards primarily physical and technical skills. Allusion is made to the suggestion that this could ultimately potentially enhance effectiveness with clients and employability prospects. In summary, a focus on critical incident method early in education and training processes has the potential to equip practitioners with the holistic and complex set of skills required in the contemporary outdoor workplace.

Key words: critical incident, reflection, context, skills, outdoors. 


\section{Introduction.}

Training programmes are an important way in which skills are developed in outdoor practitioners. Outdoor leaders in the United Kingdom are usually required to hold National Governing Body (NGB) qualifications (for example, British Mountaineering Council, British Canoe Union) and have practical experience in the domain in which they work both of which have been shown to have significant value to student employability (Prince, 2005; Stott, 2007; Stott, Zaitseva and Cui, 2012).

However, the problem inherent in most NGB outdoor leadership training and assessment is that it focuses almost exclusively on procedural or operational matters. Martindale and Collins (2005) refer to this as 'how to' knowledge, focusing on, for example, being able to paddle, climb, abseil or build a snow shelter and suggest that a wider range of what are often referred to as 'soft' skills. These soft skills encompass, for example, contextualized decision making in coaching and leadership, and reflective practice which are essential to developing the autonomous professional for the sophisticated modern outdoor sector. It is in these areas that vocational undergraduate programmes in the outdoors can significantly improve skill.

In wider literature on reflection, Schön's (1983) consideration of the limits of technical-rational knowledge underscores this tension, and is a basis from which to challenge dominant epistemological frameworks of outdoor leader training. Contemporary outdoor training rarely engages with the relational and perceptual 'softer' skills that underpin learning. Here, the term 'soft' indicates, by way of extended illustration: perception, emotional management, listening, understanding and the value that these skills can bring to an approach grounded in a primarily 'hard' and practical skill environment. Whilst an element of educational theory, usually associated with teaching and learning styles literature (Honey and Mumford, 2000; Pedlar, Burgoyne and Boydell, 2006), does characterize introduction of these 'softer' issues into initial training there is little work that has been conducted into how critical incident analysis and critical reflection might be employed in preparing for the realities of outdoor practice. This paper highlights some of the benefits to be gained from reflecting on critical incidents in practice and suggests that whilst NGB qualifications do not currently integrate this into their programmes, its challenging nature and importance are underscored in this example of a vocational undergraduate degree. This invites further consideration over the distinction between the training and education of outdoor leaders.

\section{Literature Review: A role for reflection and critical incident.}

Powerful testimonies exist to the value of reflective practice for both personal and professional growth in a range of practice settings (Attard, 2008; Muncey, 2005). Outdoor education subscribes to this but also borrows widely from other disciplines (Brennan, 2008; Martin ${ }_{2}$ Cashel, Wagstaff and Breunig, 2006). Whilst it is arguable that reflective practice is an 'essentially contested concept' (Gallie, 1964) the lack of consensus on a definition remains perplexing. For the purposes of the present paper, 
reflection is understood as 'cognitive processing with purpose that leads to a useful outcome' (Moon, 2004).

A better understanding of the contexts surrounding practice will facilitate the exploration of the potential role of reflection in outdoor leadership. Schön (1983) divided professional practice into two distinct areas: the 'swampy lowlands' consisting of 'messy' problems 'of the greatest human concern' and the 'high ground' where technical rigour and an objectivistrationalist positivist approach can be applied to problems 'of relatively little social importance' (Schön, 1983: 42). He argues that all too frequently many practitioners fall back on their technical approaches and training in order to solve problems within frameworks of their own knowing, the outcome of which is to ignore data that fall outside their realm of expertise. Rather than grapple with the relevance of the 'realworld' problems they prefer instead to interpret something beyond their expertise as 'discrepant' or rogue. In many ways, this is similar to Greenleaf's concept of 'critical disability' (2002) in which an individual hides behind his or her expertise and refuses to acknowledge the potential of 'not knowing'.

This is not to suggest that the outdoor leader should ignore the need for technical competencies as these are vital for practice functionality and security in what are often potentially hazardous environments. However, it does suggest that these competencies may be acquired at the expense of other equally valuable skills, especially those to deal with complex interpersonal relationships, interaction and decision-making. Schön goes so far as to recommend a professional education in which reflective conversations 'with the situation' are seen as enhancing rather than (the more commonly perceived) detracting from practitioner's skills. Such conversations are vital where experiential education is a central focus of the relationship and/or where the safety of the group has a collective element. Schön also advocates that professionals should develop awareness that their actions might have different meanings to clients than they are meant to, and that uncovering knowledge of these is essential to effective human interaction. Such reflective conversations are essential for preventing unforeseen consequences that are underpinned by conflicting interpretations. As Brykczynski (1989) shows in nursing, and Collins and Collins (2012) note for the outdoors, a great deal of practice knowledge is embedded, or rather submerged, in practice and remains unchallenged. However, as Tozer, Collins and Hathaway (2011) show in the case of expeditions, knowledge has to be surfaced and interrogated prior to it being of use. Too often, it is mistakenly assumed that the potential learning, and hence contribution to knowledge, inherent in any situation is recognized. This assumes that knowledge that is implicit in the experience is automatically accessible to practitioners when often it is not. Nevertheless, if the experience can be unpicked and contextualized with theoretical knowledge, the iterative process that occurs serves to extend practice knowledge. This is especially so if it is also encompassed by alternative perspectives from colleagues. For many outdoor leaders this course of action is problematic: with NGB training and assessment affording primacy to technical proficiency, and very often set against a background of independent decision-making and reflection (Dewey 1938; Moon 2008). Some might argue that the experience necessary to attain successive levels of technical competence confers practice awareness but 
as Senge (1993) suggests a central dilemma for organisations and individuals is that 'we learn best from experience but we never directly experience the consequences of many of our most important decisions' (p.23).

In an attempt to develop a summative model of technical and nontechnical aspects, Collins and Collins (2012) suggest that outdoor leaders have four primary control orientations to ensure safety in the practice situation: themselves, their clients, the action and the environment. This model, and in particular the action dimension, indicates a need to recognize the role of memory in being able to identify and remember an incident for later critical reflection: this is particularly problematic in highly dynamic situations where a high volume of data is constantly being refreshed (Flanagan, 1954). Problems can exist with attention, recognition, capacity, transfer and recall (Atkinson and Schiffrin, 1968; Schmidt and Wrisberg, 2007). The primacy afforded to practical knowledge during training accentuates the likelihood that recognition of cues and awareness of this are likely to dominate thinking. In other words, students who are trained primarily in technical skills (to the detriment of reflection on critical incidents) are prone to privileging practical issues and solutions. This approach quickly forms the basis for habituated responses, irrespective of the potential value afforded by deeper consideration of learning opportunities.

\section{Developing critical incidents for outdoor leaders.}

The argument thus far has suggested that training of outdoor leaders and educators should be broadened to include reflective critical incident analysis in a range of ways. This can benefit the leader's skills and, moreover, has the consequent potential to enhance the experience of the clients (although it should be noted that was not the express focus of the present study). To elaborate this further, outdoor leaders and educationalists, through critical incidents and additional techniques can critically engage with their own continued professional development (Parker, Webb and D'Souza, 1995). Furthermore, a leader's enhanced reflective practice could possibly benefit clients' learning and transfer skills (Hickman and Collins, 2014) especially in the still buoyant market for educational expeditions (Rowe, 2008). Also, it is important to remember that NGB qualifications function as a gateway into recreational leadership and also into outdoor professional and educational careers; thus, reflective practice could be used to enhance, for example, safety awareness in any form of practice but also in educational settings where it could be used to achieve broader goals.

Critical incident analysis would, prima facie, appear to be an ideal tool for enhancing the value of reflective practice and is crucial to the development of professional competence and expertise (Ghaye and Lillyman 2006; Hamlin 2004). This paper highlights some of the difficulties in optimizing that tool in a particular cohort of vocational undergraduate outdoor students. According to Powell (1989), the development of professional expertise is not singularly dependent upon 'doing the job' experience has to be synthesized with more complex processes. Critical 
incident analysis as a forensic technique is fundamental to that process and affords the development of sensitivities, attitudes and awareness that are grounded in practice (Parker and Wall, 1998). Moreover, it is also important in the development of notions of reflection-on-action (looking from outside at the action) and reflection-in-action (looking at the experience per se of the action) (Schön, 1983). While theories taught in training offer knowledge that is formal and implicit, actual practice is more complex, characterized by multiple, often-competing realities and requires the 'implicit' to be made 'explicit'. Tripp (1993) suggests that critical incidents are far more subtle than might, at first, be supposed. To Tripp, critical incidents are 'produced by the way we look at a situation, it is an interpretation of the significance of the event' (1993: 8). Far from paring critical incidents down to mere experiences, the value resides in the experiences that are selected for analysis and scrutiny so that they can be invigorated and maximized (Boud and Miller, 1996). Following Tripp's (1993) approach, any incident has the potential to be of value to outdoor leaders. However, he seems to overlook that in an environment that focuses on the technical, explicit guidance is likely to be necessary for the inexperienced practitioner. This might be particularly relevant when we consider Furedi's argument (2002) that many young people (who subsequently go on to become outdoor leaders) have grown up in inherently risk-averse societies. Here, technical skills can be acquired with surprising rapidity due to the expertise of (usually older) adventure sports coaches who are able to mediate hazardous environments with their judgmental skills, and through increased access to 'artificial adventure' sites such as climbing walls, white water courses and indoor snow slopes. Furthermore, many of those young people are the products of a commodified or sportified adventure environment (Collinet, Delandre, Schut and Lessard, 2013) that has seen their technical skill levels accelerate beyond their wider understanding of context and situation.

Outdoor leadership and reflective practice has received little critical attention in peer reviewed journals, and in comparison to the related fields of reflective practice and teaching, nursing or social work the research is sparse. Thus far we have suggested that the education of outdoor leaders is overly characterized by a focus on the acquisition of a range of technical and procedural skills. We have also argued for the consideration in outdoor leadership programmes of 'softer' skills that place the individual rather than the task or job as the point of focus. We have posited reflective practice, in the form of critical incident analysis, as an ideal tool for this development; whilst recognizing the environmental and cognitive challenges that this poses in practice. We also demonstrate the need for a mechanism to convert experience into knowledge. The paper now turns to examine these issues in a field context.

\section{Methodology.}

According to Bryman (2012) a research design establishes a framework for the collection and analysis of data and involves decisions about the priority and importance of dimensions within the investigative process. As this project sought to capture data about people in situations that required consideration of position and perspective an interpretive approach was 
adopted allowing for reality to be 'continually constructed and reinvented' (Coakley and Dunning, 2000: 78). An opportunistic stance was taken (Anderson, 2006) with a purposive homogenous sample group allowing for backgrounds that were likely to address specific issues of interest (Teddlie and Yu, 2007).

After considering the resources available to the project in terms of credibility, accessibility, time, cost and skill, focus groups and interviews were selected as the most appropriate methods of data collection. These are seen as appropriate to data collection in natural settings (Hagger and Chatzirartis, 2011). Internal validity was maintained through data being shared with colleagues and the support of two 'critical friends'. Following, inductive approaches, the data findings are pertinent to the sample and there are no automatic claims to broad generalizability (Yin, 2014; Stake, 1995). We follow, Giacobbi, Poczwardowski and Hager (2005) and broadly argue that meaningful research should uncover research-informed truths that inform practice within specific contexts. In the dynamic and evolving world of professional practice, hypotheses and theories derived from this type of enquiry must remain provisional and constantly exposed to reevaluation in order to understand change (Corbin and Strauss, 2008). Thus, resolving disputes over how data are generated and managed should be focused on its currency in the local context. In line with this and the study sample size Interpretative Phenomenological Analysis (IPA) was chosen to analyse the data. The focus of critical incidents emerging from this analysis was not dictated by numerical response, but by the variety of the data generated from the autobiographical accounts of the participants, and it is to these that we will now turn.

\section{Findings and Discussion.}

From the IPA analysis, and input from critical friends on the sample, the following themes emerged as most appropriate for deeper critical consideration:

- Difficulties identifying critical incidents;

- Technical proficiency;

- Interpersonal relationships;

- Developing a sense of professional responsibilities;

- Connecting theory to practice.

\section{Difficulties identifying critical incidents.}

Feedback from participants indicated three main problems with critical incidents for outdoor leaders. The first was in maintaining their thoughts beyond the immediate present. This parallels work with student teachers where immediacy of focus, especially for the less experienced is 
challenging (Hamlin, 1994; Hatton and Smith, 1995). One participant observed that:

\begin{abstract}
'whatever the activities, and I was...canoeing, kayaking and windsurfing, l'd have one eye on my clients, one making sure that I wasn't making a fool of myself and another on the weather; considering I needed three eyes at least, I hadn't got time to think about anything except what I was doing at the time'. (Respondent D, 2010).
\end{abstract}

This supports the notion that, in common with other highly dynamic environments, practitioners refresh such high volumes of information in short term memory then transfer to long-term memory for storage but that later retrieval is difficult.

The second problem concerned methods of data capture. Students were encouraged to try digital voice recorders, but these were unreliable with poor battery life, especially under cold conditions. An A5 notebook and a pencil proved more suitable. Entries could be organized to record time, date and location; either double-spaced or written on one side only to allow for reflection. While simple, this functioned well. In order to bring a degree of structure to the writing process a range of models were suggested with the majority of students opting for the $3 \mathrm{i}$ approach adapted for outdoor educators (Hickman and Palmer, 2012) which involves a simple three-line capture of trigger words under the headings of 'Information-Inference-Implication'. This model invites the user to enter the 'soft world' of analysis and to include subjective information such as the values, sensing, feeling and imagining associated with a critical incident. The aim is not to generate an objective 'generalizable' account but to be able to locate personal responses in a specifically local context and in doing so recognize more clearly one's opportunities to understand and learn.

Under 'Information', the perceived situation is recorded; the immediacy and significance of meaning is registered under 'Inference'; finally, its connection to both personal and professional practice is signified through 'Implication'. The model was developed through work with professional expedition leaders and was designed to analyze data quickly under difficult circumstances. Other models were generally considered to be too complex for use in field conditions (Barker and Cole, 2009). An example serves to illustrate one such entry in the field context. After a morning staff meeting Respondent I recorded in note form: "II/ - Punctuality. Meetings. Buses. Meals. 12/ - Schedules. Tight. All planned. 13/ - Time = money \& timekeeping = pro skill". Returning to this later, and observing on the opposite sheet of paper, left intentionally blank for the purpose, Respondent I commented: "Stuff is so tightly planned. A minute late here or there means a knock on for somebody else, and eventually somebody is ten minutes late. If that's with the airport transfers that's soooo bad business. I know why $X(\mathrm{Cl}-$ Chief Instructor) keeps telling us to set our watches five minutes' fast".

The third difficulty relating to critical incidents was in 'finding' the critical incident (Ghaye and Lillyman, 2006). Discussion highlighted the need for 
terminological clarity, particularly with the word 'critical' itself. More than one participant associated 'critical' with dangerous:

'(because) we were working with kids, well, up to about the age of 17, everything was so organised that there wasn't really any danger, nothing 'critical' so to speak'. (Respondent K, 2010).

Similar terminological issues surrounded the way in which 'problems' were conceptualized. Respondent M continued:

'I know we were supposed to look for 'problems' with everything we did, and for a while I tried hard to....but there weren't any really, and if there were occasionally, I could just ask a senior instructor for the answer'.

This reflects a need to interrogate terminology more robustly prior to workbased learning and to avoid assumptions about common meanings for words and concepts. Overall, respondents indicated that they found it challenging to discern critical incidents as such, and ways to make critical incidents more accessible is needed. Although extensive research has been carried out into critical incidents, no previous work has investigated terminological problems encountered by vocational undergraduate outdoor students, and this paper indicates that this is an important issue for further research.

The work environment was often perceived as being predictable inducing a status of 'technicians' rather than professionals operating in a risk environment requiring informed and autonomous decision-making. This highlights a potential problem with commodified adventure and its marketing to a mass audience (Beames and Varley, 2013). As delivery roles become specialized a division of labour increasingly characterizes them: as in other sectors, employers' visions determine and shape the demands made on employees. It can be speculated that in the outdoors this might lead to a divergence of leadership roles in which 'technicians' report to 'professionals', that critical incident analysis becomes tiered accordingly, and that training and education assume discrete differences. In the context of this paper, the focus is on the education of autonomous professionals.

\section{Technical proficiency.}

Technical issues were reported as the major focus of critical incidents, for example:

'if I want to get on, I need to improve the range of tickets (NGB qualifications) I have' (Respondent S, 2010);

Having the opportunity to develop the skills necessary for assessment was the reason that some students chose their particular work based learning, as one observed: 
'I got took on with training only and the promise of a free assessment if I was good enough at the end of the season; I was, but only because I'd concentrated on it so much...for me, the journal was more like a log book, only where I could work out moves as well as write about critical incidents' (Respondent C, 2010).

Amongst peers technical skills established status and value:

'at the end of the day, it's important to look good; clients might not know whether you can climb or canoe, but your mates on camp will...and they notice when you get back to uni as well' (Respondent R, 2010).

Such confessions were very revealing. Schutz (1973) argues that social reality is constantly being renegotiated as a consequence of the everyday actions of individuals. Thus in environments where routinized physical techniques and skills are a daily focus, they soon become a valuable currency affirming the status and attractiveness of the possessors.

The focus on technical skills can also be interpreted from a leadership perspective. Haslam, Reicher and Platow (2011) argue that leaders are increasingly entrepreneurial in terms of establishing their situational identity. Across the work-based learning environments, participants were responsible for the delivery of 'adventure' activities and thus appropriated relevant skills as a base for their power and status. Familiarity with appropriate 'props' (i.e. equipment) served to reinforce this (Grint, 2005). Technical performance is also a way in which sense and order can be imposed on everyday life (Dyck, 2000) and an important aspect for those preparing for active employment. Individuals create 'collective intentionality' - a message to join the dominant group is transmitted through the adoption of its common practices (Searle, 2010).

Whilst these hypotheses might begin to explain why participants in this study prioritized technical skills in their critical incidents, it still remains that an exclusive focus on these creates a myopic vision of the skills necessary for the workplace. Overall, it clearly demonstrated the actual challenge of moving from the technical to the reflection on critical incidents. This was echoed in many regards throughout the data and the research contributed to an

\section{Interpersonal relationships.}

The main focus of interpersonal relationships for participants was between peers and senior staff, with clients remaining largely anonymous. One working as a trainee raft guide observed:

'we get a group for a day and we teach them to climb, simple stuff but a big adventure for most...it would be nice to get to know the kids more, but we don't have time...safety and names is all that counts...the next day they go off on different activities and we're history' (Respondent I, 2010). 
Data underlined Loynes' concept of 'adventure in a bun' (1998) and highlighted the impact of the way that adventure has been commodified and mass-marketed. This can undermine the cultural value of working with diverse groups in an outdoor context and lead to the role of the instructor being perceived by clients as little more than a technician. One participant compared her role to that of fairground staff from her childhood, 'make sure they're strapped in right, then let them go afterwards... we don't even need to take their money' (Respondent E).

One undergraduate who had taught coasteering, a cross between 'adventure swimming, and canyoning, commented '(clients) all think they're in the ESPN X-Games', an interesting observation when it is considered that the main audience for X-Games, which have included bungee jumping, skateboarding and snow sports, have an average audience age of 20 years (Thorpe and Wheaton, 2011). In this context, those at the interface of delivery are no longer imparting expert knowledge but managing the safe delivery of the activity. More than one participant commented that client interaction was reduced mainly to safety checks and encouragement rather than anything deeper.

When critical incidents did actually focus on interpersonal relationships they were orientated towards those who had become surrogate families: peers and immediate line managers, during the work experiences. Almost exclusively, these were associated with problems, for example:

'I'm so frustrated; I asked to be taken off climbing and put on archery so that I can get an extra ticket (NGB qualification) but (my line manager) doesn't seem to be listening' (Respondent S, 2010).

When the sample was encouraged to analyse their critical incidents, most also agreed that their journal entries were broadly descriptive, egocentric and lacking in depth and sophistication.

\section{Developing a sense of professional responsibilities.}

Critical incidents provided a focus to explore emergent concepts of what it meant to be professional and included aspects of self-presentation, language, discourse and key self-management skills such as punctuality and organization. We suggest that depth of learning here through reflection on critical incidents is relative, and that a deeper appreciation of what it is to be professional in terms of the examples above, whether in the role of technician or junior manager, is relevant to a sector neonate but not someone with more experience. Depth of learning is contextual to the role that is occupied.

Self-presentation was recognized as having multiple constructs giving access to power and status:

'because I can drive, part of my job included meeting and greeting head teachers and teachers and I wasn't allowed to wear shorts and Tevas (sandals) when I did. Like at first I really resented this, really didn't like it because it wasn't who I am, wasn't what I really wanted 
to do...(but) the more I thought, the more I realized that the job needed a responsible face with these people, people who make the decisions... and it was up to me to be that responsible person...it was quite a compliment, I guess, but at first, no, I didn't like it' (Respondent D, 2010).

Another participant who had worked on an educational expedition to northern Canada highlighted how she had used 'props', in the form of the specialized canoeing kit to impress her expert power on newly arrived clients from the UK:

'I made sure my (throw) line and pin kit (rescue equipment) were outside my tent when I gave my first brief, and several sets of blades (canoe paddles) just so they could get an idea that I knew what I was talking about...after all, I was only about three years older than them and I needed them to know they could trust me... and that I wasn't one of them, like to have some space between us' (Respondent A, 2010).

This reflects a developing awareness of different skills being necessary in the workplace and also how to use them. Respondent A also acknowledges the importance of self-managing the slender age gap between herself and clients, something overlooked by others. Furthermore in the instances above there is also the emergence of a degree of confidence in being able to use developing skills, something recognized in other practice areas such as healthcare (Rademacher, Simpson and Marcdante, 2010) and teaching (Hanhimaki and Tirri, 2009).

Being required to work to demanding time schedules also featured repeatedly in critical incidents. High volumes of client turnover with tight activity plans, daily meetings and often only one day's rest per week in the high season meant that punctuality and the capacity to cope under pressure were at a premium. Respondent $D$ noted:

'I have to be in six places each day and in every one of those I'm expected to make things work....if I'm late, there's a knock on to the next... and I'm responsible' (2010).

Whilst challenging, these demands forged the skills of being able to cope under pressure and to prioritize demands; two skills acknowledged as being vital for graduate employment but underdeveloped in many (Paton, 2013).

\section{Connecting theory to practice.}

Critical incident analysis is highly effective in the transfer of theory to practice, in the transition from the theoretical to the applied environment, and in the development of professionalism (Brookfield, 1995; McFee, 2011). Higher education students increasingly scrutinize this, as do political reformers, who maintain that knowledge of an academic subject is no longer sufficient to enhance graduate employment prospects (Fallows and Steven, 2000). It is in the applied environment that sense making is 
optimized and both employability and deployability increased (Weick, 1995). This present study highlights ways that aspirant outdoor leaders might use critical incidents to attempt to relate theory to practice and then enhance the understanding of that practice. It explores the bridge between theory and practice and more importantly indicates the value of learning through experiences that exist beyond the purely technical (Beard and Wilson, 2013). Furthermore, an important consideration is that learning through experience might or might not relate to previous theory, and might not generate 'new theory' to inform practice. Smith and Betts (2000) explore this in more detail showing that learning about practice can be informational, or about practice, locational, or in practice, and experiential, or through practice. In the latter, structured reflection is critical to generate local understanding.

Several respondents identified the tensions between the principles of outdoor education and the requirements of the business organization. Respondent D explained:

'I'm beginning to understand stuff we covered in lectures, see how it's working up close and at first hand....it's interesting that everything is branded 'adventure', the 'adventure course or challenge', adventure this and adventure that, but really there isn't any adventure, at least where I was'. (2010).

whilst another observed:

'a camp canoeing instructor is a manager...only the space and experience that needs to be managed is different...the adventure's in the head of the client...we sold the idea of being extreme....and it sold well'. (Respondent L, 2010).

In the Hickman and Palmer (2012) model, this is evidence of the critical incident causing the student to 'notice' and identify information. Whilst these seem to be relatively superficial reflections, they can provide the catalyst and the platform for deeper considerations that are able to be developed as a skill in formal classroom situations and then transferred beyond the theoretical and into practice as the student becomes more independent. As Gray, Hodgson and Heaney (2011) point out, few novice practitioners appreciate the 'how to' to develop themselves to achieve their potential and advocates structured reflective practice to help resolve this. Ways by which inferences and implications for latent professionalism can be drawn out were discussed in the more social environment of the seminar room, and led to suggestions that practice should adopt more supportive collegiate approaches to reflection that would mirror the problem solving clusters generated by a 'campfire approach'.

Respondent $L$ went on to articulate how the seriousness of the workplace was brought into stark relief:

'I hadn't thought about it before, but there was nearly a fatality when someone got trapped underneath a boat. They were so scared, and so was I, not really the sort of thing I should've seen at 
my age. It made me think about my responsibilities. Even at 20 I ('ve) got tons of responsibility, like for kids' lives. We all go to camp thinking that it's a chance to do loads of interesting things, to travel, but really it's not a game' (Respondent L, 2010).

Another who had worked as an assistant expedition leader on an extended educational trip to the Arctic reflected on the ways that her clients attributed meaning to what was going on, the problems this caused for her and a growing awareness of social perceptions of role:

'When some of the boys got out of their depth, they'd start acting about, like they were at school, I guess, and this was the way they hid their fears. It was sort of like they were in class and didn't want to show that they didn't know, so played the fool instead' (Respondent G, 2010).

She was referring here to the theory that resources determine the interpretation of events, and for young people these can be limited. Thus, they often revert to familiar behaviours that give them credibility in their known cultural settings. She concluded: 'I need to be able to do is handle people and realize that when they're out of their depth they act funny, not ha-ha, but in ways that just don't suit (the situation).'

This is an intelligent insight from the student but is still at the Information stage of the 3i Model and in need of deeper critical engagement. For example, if adventure is defined by having an "uncertain outcome" (New Zealand Mountain Safety Council, 1993: 9) not only is there a paradox in that commodified adventure is expressly designed to be predictable and safe, but consideration could also be given to how an activity that causes reversion to familiar behaviour fits within an experience that was probably intended to work in an entirely opposite way.

A number of scholars show that reflection-on-action (Schön, 1983) helps people to adapt to, and cope with, unknown environments (Ghaye and Lillyman, 2006; Smith and Trede, 2013). The instances given above are examples of the ways in which young practitioners mediate their experiences with reference to theories learned in more formal classroom settings. By encouraging them to develop a framework for incidents to be captured and then subjected to later critical consideration their opportunities to extract learning from the experiences were improved.

\section{Conclusion.}

This paper established a premise that outdoor leadership training, particularly that provided by NGB Award schemes, concentrates overly on the development of procedural skills at the expense of equally crucial 'soft' skills. It also set out to determine how a group of undergraduate aspirant outdoor professionals engaged with critical incidents during an extended block of work-experience and to consider how those incidents were perceived. Whilst not to detract from the value of skills that allow for the management of the physical activity and the natural environment, it has been argued that there is a need for practitioners to develop the softer 
skills underpinning complex human perceptions and interactions, and to take ownership of their own development. Furthermore, as illustrated by, but not limited to, the example of educational expeditions, there is also a need to foster the outdoor leader skills necessary in order to try to optimize clients' experiences, particularly where personal development and transfer beyond the event are concerned.

The data show that although procedural skills figured highly in the respondents' reflections this was not entirely at the expense of intra- and inter-personal skills. However, it was the reflecting on the action in the critical incidents that generated the potential for deeper learning, for example about power, concepts of professionalism, connections between theory and practice, and how learning can occur through experience, and that reconciliation between the potential and actual value of these requires more work. The data support the notion that a more sophisticated approach than is currently offered by NGBs is required to develop young undergraduate outdoor leaders. It also suggests that an obstacle to developing such skills is the lack of an acknowledged method by which critical incidents can be easily captured for later consideration. Other dynamic environments, such as, for example, surgery, which does not offer practitioners the opportunity to stop and record, routinely film procedures for later analysis: an impractical solution for the outdoor sector.

The context in which the critical incidents were generated shows that the work-based problems that arose and were dealt with by this cohort were broader than the situations for which current NGB training prepares them. As the growing outdoor labour market generates increased employment opportunities there have been calls for the creation of a more professional collective identity (Potter, Socha and O'Connell, 2012) and closer relationships between industry and academia to shape the professionals of the future (Humberstone and Brown, 2006; Frean, 2008). The NGB focus on technical proficiency is in need of reconsideration as to whether it is producing people with the broad range of skills that are currently in demand. This paper has highlighted how the use of reflective practice to analyze critical incidents generated in undergraduate work experience can contribute to developing those extra skills. The evidence presented here functioned as a platform for further investigation into the role of critical incidents in developing professionalism, and the results form part on ongoing and future studies.

\section{References.}

Anderson, L. (2006). Analytic Autoethnography. Journal of Contemporary Ethnography. 35 (4), 373-395.

Atkinson, R.C. and Shiffrin, R.M. (1968). Human memory: A proposed system and its control processes. In Spence, K.W. and Spence, J.T. The psychology of learning and motivation. New York: Academic Press. 89-195. 
Attard, K. (2008). Uncertainty for the reflective practitioner: a blessing in disguise. Reflective Practice. 9 (3). 307-317.

Barker, S., and Cole, R. (2009). Brilliant Project Management: What the best project managers know, do and say. London. Pearson.

Beames, S. and Varley, P. (2013). Eat, play, shop: the Disneyization of adventure. In Taylor, S., Varley, P. and Johnston, T. (2013) (Eds). Adventure Tourism: Meanings, experience and learning. London. Routledge.

Beard, C. and Wilson, J.P. (2013). Experiential Learning: A handbook for education, training and coaching. London. Kogan Page.

Boud, D. and Miller, N. (1996). Working with Experience: Animating Learning. London. Routledge.

Brennan, D. (2008). Older Adults in Adventure Education: Making Meaning of Older Adults' Inner Experiences of Experiential Education. Milton Keynes. Lightening Source.

Brookfield, S. (1995). Becoming a Critically Reflective Teacher. San Fransisco. Jossey-Bass.

Brykczynski, K.A. (1989). An Interpretive Study Describing the Clinical Judgement of Nurse Practitioners. Research and Theory for Nursing Practice, 3 (2), 75-104.

Bryman, A. (2012). Social Research Methods. Oxford. OUP.

Coakley, J. and Dunning, E. (2000). Handbook of Sports Studies. London. Sage.

Collinet, C., Delalandre, M., Schut, P and Lessard, C. (2013). Physical Practices and Sportification: Between Institutionalisation and Standardisation: The Example of Three Activities in France. The International Journal of the History of Sport, 30 (9), 989-1007.

Collins, L. \& Collins, D. (2012). Conceptualizing the adventure-sports coach. Journal of Adventure Education and Outdoor Learning. 12 (1), 8193.

Corbin, J.M. and Strauss, A. (2008). Basics of Qualitative Research: Techniques and Procedures for Developing Grounded Theory. London. Sage.

Dewey, J. (1933). How we think: A Restatement of the Relation of Reflective Thinking to the Educative Process. New York. DC Heath and Co.

Dewey, J. (1938). Experience and education. New York. Collier.

Dyck, N. (Ed). (2000). Games, Sports and Cultures. Oxford. Berg. 
Fallows, S. and Steven C. (2000). Building employability skills into the higher education curriculum: a university-wide initiative. Education + Training, 42 (2), 75-83.

Flanagan J.C. (1954). The Critical Incident Technique. Psychological Bulletin. 51 (4). 327-358.

Furedi, F. (2001). Paranoid Parenting. London. Allen Lane.

Frean, A. (2008). Give students lessons on how to get up in the morning, business tells universities. The Times. $18^{\text {th }}$ September, 5 .

Furedi, F. (2002). Paranoid Parenting: why ignoring the experts may be best for your child. Chicago, II. Chicago Review Press.

Gallie, W.B. (1964). Essentially Contested Concepts. In Gallie, W.B.

Philosophy and the Historical Understanding. Chatto and Windus. London. 157-191.

Ghaye, T. and Lillyman, S. (2006). Learning journals and critical incidents: reflective practice for health care professionals. Wiltshire. Quay Books.

Giacobbi, P.R., Poczwardowski, A. \& Hager, P.F. (2005). A Pragmatic Research Philosophy for Sport Psychology. Sport Psychologist. 19 (1), 1831.

Gray, P. Hodgson, C. and Heaney, C. (2011). Enhancing professional development for the adventure educator. In Berry M. and Hodgson, C.

(Eds). Adventure Education: An Introduction. London. Routledge. 236-256.

Greenleaf, R.K. (2002). Servant Leadership: A Journey into the Nature of Legitimate Power \& Greatness. New York. Paulist Press.

Grint, K. (2005). Leadership: Limits and Possibilities. Hampshire. Palgrave Macmillan.

Hagger, M.S. \& Chatzirarantis, N.L.D. (2011). Never the twain shall meet? Quantitative psychological researchers' perspectives on qualitative research. Qualitative Research in Sport, Exercise and Health, 3 (3), 266277.

Hahnimaki, E. and Tirri, K. (2009). Education for ethically sensitive teaching in critical incidents at school. The Journal of Education for Teaching. 35 (2), 107-121.

Hamlin, K.D. (2004). Beginning the journey: supporting reflection in early field experiences. Reflective Practice: International and Multidisciplinary Perspectives. 5 (2), 167-179.

Haslam, S.A., Reicher, S.D. \& Platow, M.J. (2011). The New Psychology of Leadership: Identity, Influence and Power. Hove. Psychology Press. 
Hatton, N. and Smith, D. (1995). Reflection in teacher education: towards definition and implementation. Teaching and Teacher Education. 11 (1). 33-49.

Hickman, M. and Collins, D. (2014). The operation and impact of participants' trans-expedition reflective practice: structuring and optimizing the transfer process. Pastoral Care in Education. 32 (2), 157163.

Hickman, M. and Palmer, C. (2012). The 3i Model: A guide to critical reflective analysis in outdoor education - information, inference and implication. Presentation at the British Educational Research Association Annual Conference, London Institute of Education, $4^{\text {th }}-6^{\text {th }}$ September.

Honey, P. and Mumford. A. (2000) The Learning Style Questionnaire: 80 Item Version. UK. Peter Honey Publications.

Humberstone B. and Brown H. (2006). Outdoor Studies and Higher Education in the $21^{\text {st }}$ Century. IN Humberstone B. and Brown H. (Eds). Shaping the Outdoor Profession through Higher Education: Creative. Diversity in Outdoor Studies Courses in Higher Education in the UK. Penrith. Institute for Outdoor Learning. 1-6.

Loynes, C. (1998). Adventure in a Bun. Journal of Experiential Education. 21 (1), 35-39.

Martin, B., Cashel, C., Wagstaff, M. \& Breunig, M. (2006). Outdoor Leadership: Theory and Practice. Champaign, II. Human Kinetics.

Martindale, A. and Collins, D. (2005) Professional judgment and decisionmaking: The role of intention for impact, The Sport Psychologist, 19 (3), 303-317.

McFee, G. (2011). Ethics, Knowledge and Truth in Sports Research: An epistemology of sport. London. Routledge.

Moon, J. (2004). A Handbook of Reflective and Experiential Learning: Theory and Practice. London. Routledge-Falmer.

Moon, J.A. (2008). Reflection in Learning and Professional Development. London. Routledge-Falmer.

Muncey, T. (2005). Doing autoethnography. International Journal of Qualitative Methods. 4 (1). 1-12.

New Zealand Mountain Safety Council. (1993). Managing Risks in Outdoor Activities. Wellington. NZMSC

Parker, D.L., Webb, J. and D'Souza, B. (1995). The value of critical incident analysis as an educational tool and its relationship to experiential learning. Nurse Education Today. 15 (2), 111-116.

Parker, S. and Wall, T. (1998). Job and Work Design: Organizing Work to Promote Well-Being and Effectiveness. London. Sage. 
Paton, G. (2013). University leavers lack the essential skills for work, employers warn. The Telegraph. www.telegraph.co.uk (Accessed 13.12.13)

Pedlar, M., Burgoyne, J. and Boydell, T. (2006). A Manager's Guide to SelfDevelopment. Maidenhead. McGrawHill.

Potter, T.G., Socha, T.L. and O'Connell, T.S. (2012). Outdoor adventure education (OAE) in higher education: characteristics of successful university degree programmes. Journal of Adventure Education and Outdoor Learning. 12 (2). 99-119.

Powell, J.H. (1989). The reflective practitioner in nursing. Journal of Advanced Nursing. 14 (10), 824-832.

Prince, H. (2005). Graduate pathways: A longitudinal study of graduates in outdoor studies in the UK. Journal of Adventure Education and Outdoor Learning. 5 (1), 21-33.

Rademacher, R. Simpson, D. and Marcdante, K. (2010). Critical incidents as a technique for teaching professionalism. Med Teach. 32 (3), 244-249.

Rowe, M. (2008). The credibility gap. Geographical. August, 46-53.

Schön, D. (1983). The Reflective Practitioner: How Professionals Think In Action. Aldershot. Ashgate.

Searle, J. (2010). Making the Social World: The Structure of Human Civilization. Oxford. OUP.

Senge, P. (1993). The Fifth Discipline: The Art and Practice of the Learning Organization. London. Century.

Schmidt, R. and Wrisberg, C.A. (2007). Motor Learning and Performance: A Situation-Based Approach. Champaign, II. Human Kinetics.

Schutz, A. (1973). Common-sense and Scientific Interpretation of Human Action. In Schutz, A. (Ed). Collected Papers: The Problem of Social Reality. The Hague. Martin Nijhoff.

Smith, M. and Trede, F. (2013). Reflective practice in the transition phase from university students to novice graduate: implications for teaching reflective practice. Higher Education Research and Development. 32 (4), 632-645.

Smith, R. and Betts, M. (2000). Learning as partners: Realising the potential of work-based learning. Journal of Vocational Education and Training. 52 (4), 589-604.

Stake, R.E. (1995). The Art of Case Study Research. London: Sage Publications. 
Stott, T.A. (2007). Adding value to students in higher education: a 5-year analysis of student attainment of National Governing Body Awards in a UK Outdoor Education Degree Programme. Journal of Adventure Education and Outdoor Learning. 7 (2), 141-160.

Stott, T.A., Zaitseva, E. and Cui, V. (2012). A Longitudinal Study of Employability in a UK Outdoor Education Degree Programme using Fresher and Graduate Identities. Studies in Higher Education. 39 (5), 711-733.

Teddlie, C. \& Yu, F. (2007). Mixed Methods Sampling: A Typology With Examples. Journal of Mixed Methods Research, 1 (1), 77-100.

Thorpe, H. and Wheaton, B. (2011). 'Generation X Games', action sports and the Olympic movement: understanding the cultural politics of incorporation. Sociology, 45 (5), 830-847.

Tozer, M., Collins, D. and Hathaway, T. (2011). Learning through expeditions: the need for method as well as opportunity - a response to Allison and Von Wald (2010). Pastoral Care in Education, 29 (1), 51-56.

Tripp, D. (1993). Critical Incidents in Teaching: Developing Professional Judgement. London. Routledge.

Weick, K.E. (1995). Sense-making in Organizations. London. Sage.

Yin, R.K. (2014). Case Study Research: Design and Methods. London. Sage. 